\title{
Low Benthic Oxygen and High Internal Phosphorus-Loading are Strongly Associated With the Invasive Macrophyte Nitellopsis obtusa (starry stonewort) in a Large, Polymictic Lake
}

\author{
Tyler J. Harrow-Lyle* and Andrea E. Kirkwood \\ Faculty of Science, Ontario Tech University, Oshawa, ON, Canada
}

Lake Scugog is an important headwater to the Trent Severn-Waterway in Ontario, Canada. In recent years, notable ecosystem-level changes have occurred coinciding with the emergence of the non-native invasive charophyte Nitellopsis obtusa. Despite N. obtusa arriving in North America in the early 1970s, studies documenting the impact of N. obtusa on invaded ecosystems are scarce. Given the increasing dominance of $N$. obtusa in inland waters of the Great Lakes basin, we investigated the ecosystem-level impacts of $N$. obtusa

OPEN ACCESS

Edited by:

Teresa Ferreira,

University of Lisbon, Portugal

Reviewed by:

Mateja Germ,

University of Ljubljana, Slovenia

Francisca Aguiar.

University of Lisbon, Portugal

*Correspondence:

Tyler J. Harrow-Lyle harrowlyle.tyler@gmail.com

Specialty section: This article was submitted to

Freshwater Science,

a section of the journal

Frontiers in Environmental Science

Received: 02 July 2021 Accepted: 10 August 2021 Published: 19 August 2021

Citation:

Harrow-Lyle TJ and Kirkwood AE (2021) Low Benthic Oxygen and High

Internal Phosphorus-Loading are Strongly Associated With the Invasive Macrophyte Nitellopsis obtusa (starry stonewort) in a Large, Polymictic Lake.

Front. Environ. Sci. 9:735509.

doi: 10.3389/fenvs.2021.735509 in Lake Scugog over a 3-year period. We show for the first time a strong association between $N$. obtusa occurrence and biomass with benthic anoxia in this shallow, polymictic lake. Benthic dissolved oxygen concentrations were significantly lower $(p$-value $<0.001)$ at sites with $N$. obtusa compared to sites without N. obtusa. Additionally, N. obtusa biomass was a negative predictor of near-bed oxygen concentration $\left(R^{2}=0.59, p\right.$-value $\left.<0.001\right)$. Knowing that anoxia can promote the internal loading of phosphorus, we measured soluble reactive phosphorus (SRP) in the pore-water of sediments at each site, and found $N$. obtusa biomass explained $90 \%$ of sediment pore-water SRP $\left(R^{2}=0.90, p\right.$-value < 0.001). These notable associations between $N$. obtusa and key lake elements indicates that $N$. obtusa may be acting as an ecosystem engineer in invaded lakes by altering the biogeochemical fate of oxygen and phosphorus.

\begin{abstract}
Keywords: Nitellopsis obtusa, invasive species, dissolved oxygen, thermal stratification, soluble reactive phosphorous, ecosystem engineer
\end{abstract}

\section{INTRODUCTION}

Nitellopsis obtusa (Desv.) J. Groves, 1919, is a non-native invasive macrophyte in lakes and coastal wetlands of eastern North America. Native to Eurasia, N. obtusa is a macroalga belonging to the Characeae family. Initially identified in the St. Lawrence River in 1974 (Karol and Sleith, 2017), rapid expansion to lakes of the United States and Canada began just over a decade ago (Larkin et al., 2018). In Ontario, N. obtusa populations have been confirmed in Lake Simcoe as early as 2008 (Ginn et al., 2021), and Presqu'ile Bay in 2015 (Midwood et al., 2016). Despite increasing range of distribution in the Great Lakes basin, information pertaining to the negative effects on ecosystem processes, habitat structure, and biota associated with N. obtusa invasion are in short supply and remain largely anecdotal. 
When dense beds of $N$. obtusa form in invaded lakes, other macrophyte taxa, non-native and native alike, are displaced and native fish habitat is severely altered (Pullman and Crawford, 2010; Brainard and Schulz, 2017; Harrow-Lyle and Kirkwood, 2020a; Ginn et al., 2021). The N. obtusa invasion of Lake Scugog, a large, shallow lake in southern Ontario, Canada, likely occurred in the early-2000s, but was first documented in 2015. Due to an agriculture-dominant watershed, and nutrient rich waters, Lake Scugog has always supported a prolific macrophyte community (Kawartha Conservation, 2010). Similar to other macrophyte dominated systems, the high abundance of aquatic vegetation has controlled available nutrient concentrations, and added sediment stability, decreasing internal loading (Sand-Jensen and Borum, 1991). Although loading of phosphorus from land-use activities in Lake Scugog's watershed has been a problem historically, over the past 20 years, decreased phosphorus loadings have caused a shift to meso-eutrophic conditions supporting a vibrant and diverse macrophyte community (Kawartha Conservation, unpublished data).

We surveyed N. obtusa across both basins in Lake Scugog from 2016-2019, and saw a clear increase in the dominance of this invasive species in the macrophyte community (Harrow-Lyle and Kirkwood, 2020a). We also documented the first known incidents of Microcystis blooms in Lake Scugog, and determined that $N$. obtusa was a significant biological driver of Microcystis biomass (Harrow-Lyle and Kirkwood, 2020b). To improve our understanding of the ecosystem-level impacts of $N$. obtusa, and its role in Microcystis blooms in Lake Scugog, we analyzed 3-years (2017-2019) of benthic dissolved oxygen (DO) and sediment soluble reactive phosphorus (SRP) from twelve sites spanning the entire lake.
Additionally, we examined sediment pore-water SRP in response to $N$. obtusa biomass, based on the premise that depleted benthic DO concentrations would enhance internal phosphorus loading (Lake et al., 2007). The hypolimnion of productive lakes can typically become anoxic by mid-summer due to high biological oxygen demand. When oxygen is depleted near the lake bed, redox conditions shift and trigger sedimentrelease of dissolved phosphorus, including SRP. Lake Scugog is a highly productive lake, but due to a long fetch and shallow meandepth, it has been designated as polymictic (i.e., periodic mixing of water) with no persistent thermal stratification throughout the summer months (Kawartha Conservation, 2010). However, with dense beds of $N$. obtusa now occurring in parts of the lake, we conjectured that water column mixing with the atmosphere may be more subdued at those sites.

Given the emergence of thick N. obtusa beds in Lake Scugog over the study period, we wanted to test the hypotheses that 1) low benthic oxygen concentrations across Lake Scugog were associated with $N$. obtusa presence, and 2) benthic DO decreased in response to increasing $N$. obtusa biomass. Although benthic anoxia has been reported under charophyte beds previously (Kufel and Kufel, 2002), there have been no studies to date showing benthic anoxia or low DO occurring under N. obtusa beds in its native or introduced ranges. We report here for the first-time clear differences in benthic DO at sites with and without $N$. obtusa. We also detected strong statistical relationships between DO and SRP with $N$. obtusa biomass, respectively. These results infer a mechanistic role for this invasive macrophyte that impacts near-bed habitat condition. A stabilized water column and internal loading of phosphorus are also conditions known to promote Microcystis blooms (Chung

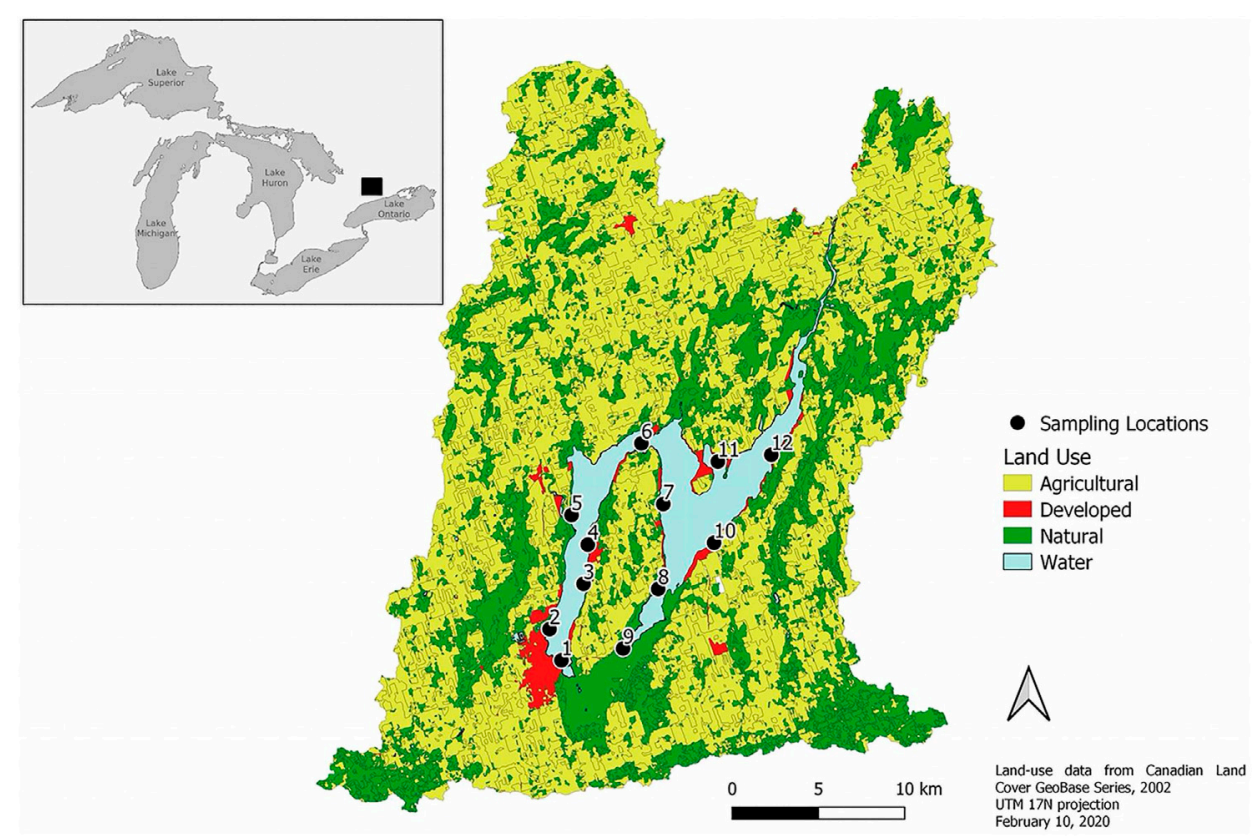

FIGURE 1 | Map of Lake Scugog, and sampling site locations, within the delineated watershed and land-use features. Sampling locations are labelled 1-12. This map was created in QGIS version 3.12.0 (QGIS Development Team, 2016). 


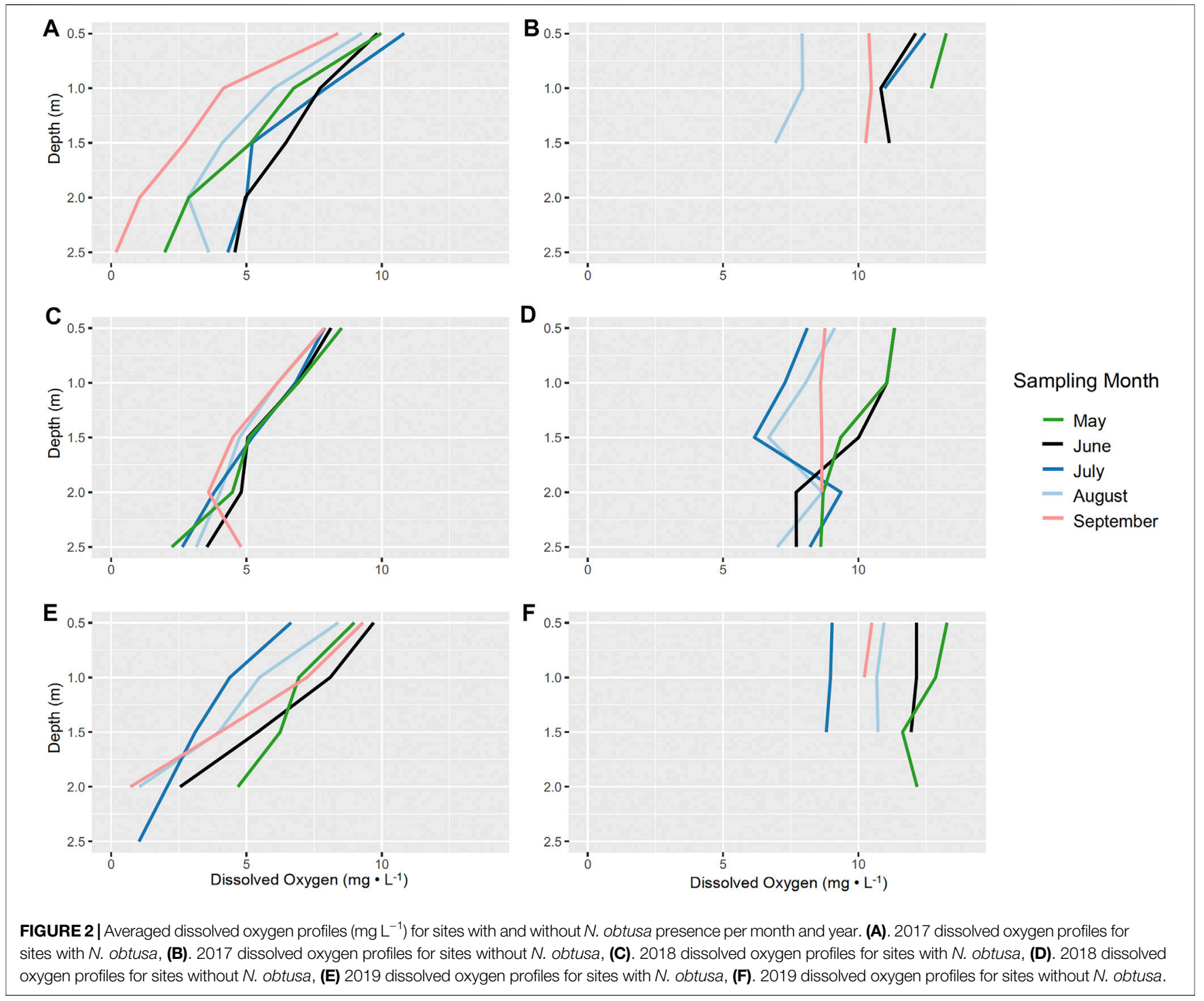

et al., 2014). Based on the physical effect that dense beds of $N$. obtusa could have on water column mixing and near-bed biogeochemistry, we propose that $N$. obtusa may be an ecosystem engineer in invaded lakes and wetlands.

\section{Methods}

Lake Scugog is a large $\left(68 \mathrm{~km}^{2}\right)$, shallow (mean depth $=1.4 \mathrm{~m}$ ) headwater reservoir located in southern Ontario, Canada (Figure 1). Twelve sampling sites were monitored from May-September over 3 years (2017-2019) with site depths spanning 1-3 $\mathrm{m}$ across the two basins. Sampling sites spanned the two lake basins with equal coverage. Sampling locations were intentionally selected to reflect historical fish spawning locations in order to determine if $N$. obtusa establishment may impact fish habitat quality. Sites 5 and 9 were inaccessible each year of sampling during September due to low water levels. DO measurements were taken at $0.5 \mathrm{~m}$ depth intervals at each of 12 sites using a YSI 6 series multiparameter probe (YSI Inc.,
Yellowsprings, Ohio, United States). Benthic DO concentrations were measured $0.5 \mathrm{~m}$ above the sediment-water interface to minimize sediment disturbance during the reading. The sonde was suspended at each depth until the reading stabilized, before recording the value.

After DO readings were completed, sediment cores were taken at each site using an NLA Gravity Corer (Hoskin Scientific, Burlington, Canada). The top $10 \mathrm{~cm}$ of each sediment core were sectioned into acid washed tubes and stored on ice until returning to the lab on the same day. Tubes were acid washed to remove residual nutrients and were well rinsed with Milli-Q water to remove residual acid. To extract pore-water, sediment samples were centrifuged at $10,000 \mathrm{~g}$ for $10 \mathrm{~min}$. Samples were stored at $-20^{\circ} \mathrm{C}$ and analysed using the modified method of Murphy and Riley (1962), developed by the Ontario Ministry of Environment (1983). Nitellopsis obtusa was collected following the rake method of Ginn (2011). Briefly, collection comprised three rake tosses that extended to the sediment at each site. 


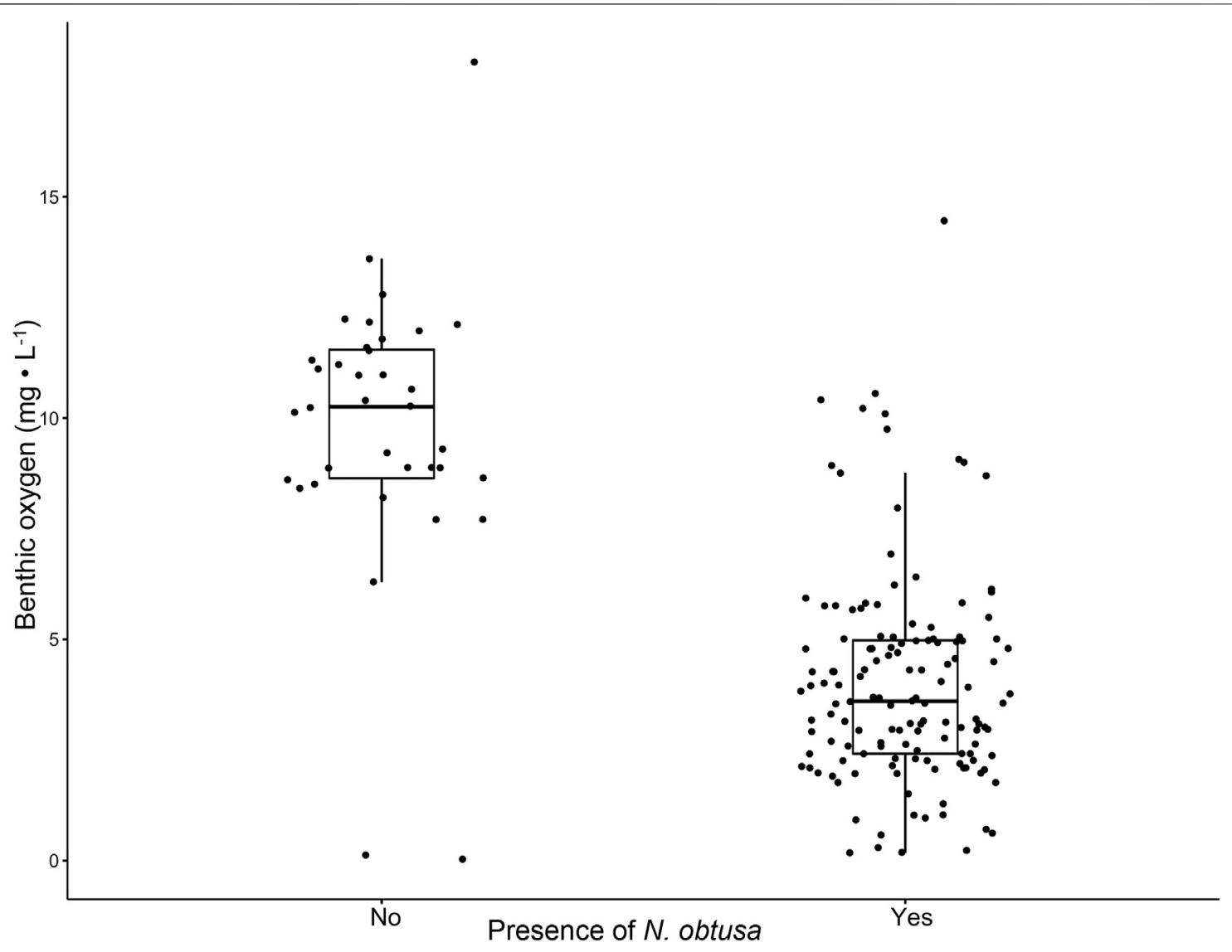

FIGURE 3 | Boxplots comparing benthic oxygen concentrations for sites with $(n=138)$ and without $(n=36) N$. obtusa presence. A Welch's $t$-test was used to compare sample means $(\alpha=0.05)$.

Samples were transported back to the laboratory, washed in reverse osmosis water, and identified following charophytes of North America (Wood, 1967), and status and strategy for Starry Stonewort [Nitellopsis obtusa (Desv. In Loisel.) J. Groves] management (Hackett et al., 2014).

Statistical analyses were conducted in $\mathrm{R}$ version 4.0.0 ( $\mathrm{R}$ Core Team, 2019) using the packages ggpubr (Kassambara, 2020), and ggplot2 (Wickham, 2016). To ensure visual accessibility of our oxygen profiles, an accessible palette was applied from the RColorBrewer package (Neuwirth, 2014). DO profiles were averaged for each sampling date and separated by years for sites with and without $N$. obtusa presence. To assess differences in benthic dissolved oxygen between sites with and without N. obtusa, a Welch's $t$-test was used due to unequal sample sizes. Linear regressions were performed with $N$. obtusa biomass (dry-weight in grams) as the independent predictor variable of benthic oxygen concentrations $\left(\mathrm{mg} \mathrm{L}^{-1}\right)$ and sediment pore-water SRP $\left(\mu \mathrm{g} \mathrm{L}^{-1}\right)$.

\section{Results and Discussion}

Studies documenting connections between aquatic macrophytes and sediment anoxia are limited (Atapaththu et al., 2018). However, dense stands of macrophytes, including those of
Characeae and Myriophyllum spicatum, are often described to regulate dissolved oxygen profiles (Frodge et al., 1990; Cardinale et al., 1997; Unmuth et al., 2000; Kufel and Kufel, 2002). Consistently over the 3-year study, sites with N. obtusa had lower DO concentrations throughout the water column (Figures 2A,C,E). Generally, sites without N. obtusa, frequently dominated by $M$. spicatum, had DO concentrations in the supersaturated range, and maintained higher concentrations throughout the water column than sites with $N$. obtusa (Figures 2B,D,F). Benthic DO concentrations were significantly different (Welch's $t$-test $p$-value $<0.001$ ) between sites with and without $N$. obtusa (Figure 3).

Not only was low benthic DO associated with $N$. obtusa presence, but $N$. obtusa biomass was a negative explanatory variable for benthic DO $\left(R^{2}=0.59\right)$ (Figure 4A) and positive explanatory variable for sediment pore-water SRP $\left(R^{2}=0.90\right)$ (Figure 4B). With phosphorus loading from the watershed apparently decreasing (Kawartha Conservation, 2010), our results are likely a reflection of the mobilization of legacy phosphorus within the ecosystem. These results clearly show a distinct water quality profile associated with $N$. obtusa in Lake Scugog, where N. obtusa appears to be a driver of benthic hypoxia-anoxia; a necessary condition for internal loading of bioavailable phosphorus from sediments. 

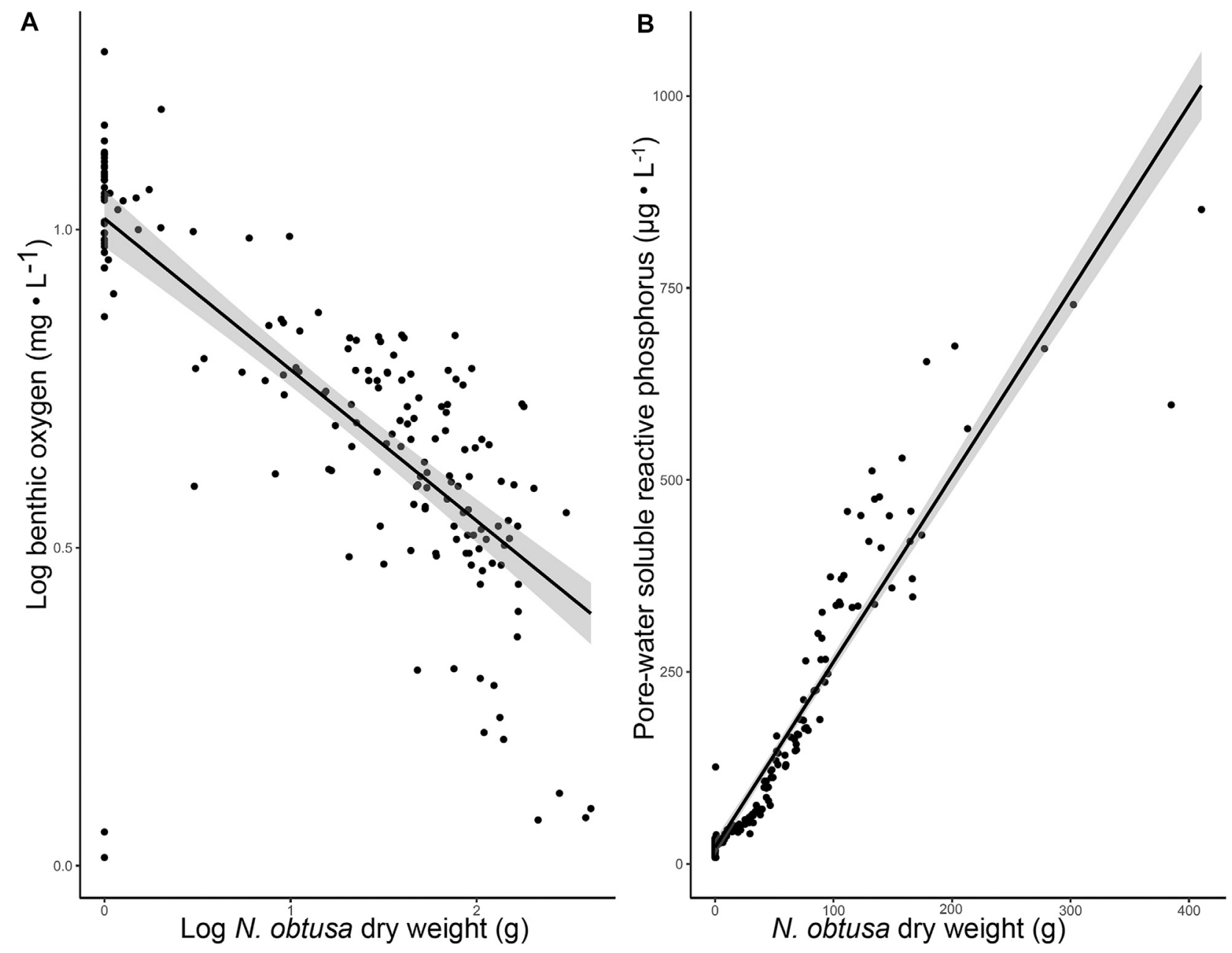

FIGURE 4 | (A). Scatter plot with regression line visualizing the relationship between Log transformed benthic DO and $N$. obtusa dry-weight $\left(R^{2}=0.59, p\right.$-value $<$ $0.001)$ (B). Scatter plot with regression line visualizing the relationship between pore-water SRP and $N$. obtusa dry-weight $\left(R^{2}=0.90, p\right.$-value $\left.<0.001\right)$.

Brainard and Schulz (2017) suggested that when dense benthic mats of $N$. obtusa undergo senescence, nutrients are released from sediments. Despite $N$. obtusa not undergoing senescence in our study, N. obtusa biomass was a very strong predictor of sediment pore-water SRP concentration. Based on the negative relationship with DO, it is likely that N. obtusa is indirectly facilitating sediment phosphorus release into the water column. Internal phosphorus loading of bioavailable phosphorus is regarded as a primary driver of cyanobacterial blooms (Bormans et al., 2016). Thus, this prominent association between N. obtusa and internal phosphorus loading in Lake Scugog infers an indirect faciliatory role in Microcystis bloom development.

Unlike other macrophytes, the life-cycle and reproductive strategies of some Characeae are dependent on hypoxic-anoxic events at the sediment water interface. Generally, Characeae that reproduce through vegetative propagules rely on viable propagule banks within the sediments (Migula, 1897). Propagules can persist in sediments for extended periods of time, however, when buried deeper than $2 \mathrm{~cm}$, the potential to germinate is lost (Bonis and Grillas, 2002). This is attributed to the necessity of hypoxic-anoxic conditions at the sediment water interface to initiate germination (Bonis and Grillas, 2002). The strong association of reduced benthic DO with increasing N. obtusa abundance in our study suggests that $N$. obtusa may alter local habitat conditions to promote propagule bank germination. This positive-feedback system may explain why $N$. obtusa is initially delayed in becoming dominant in the macrophyte community because it takes time for there to be sufficient biomass to induce hypoxic-anoxic conditions for propagules to germinate.

Dispersal and establishment of N. obtusa within invaded regions is poorly understood (Larkin et al., 2018). Generally, macrophytes can be dispersed through viable propagules and vegetative fragments (Reynolds et al., 2015; Green, 2016). Charophyte propagules have been known to be dispersed through epizoochory and endozoochory (Bonis and Grillas, 2002). However, there is mounting evidence that the majority of $N$. obtusa dispersal throughout invaded regions is occurring through watercraft movement and deployment (Sleith et al., 2015; Midwood et al., 2016; Harrow-Lyle and Kirkwood, 2021). Given our results, which document habitat alterations conducive of 
propagule germination, dispersal and establishment must be areas of focus going forward. Thus, implementing management programs that target boat launches may be effective in preventing $N$. obtusa spread, while also allowing early detection for new populations within invaded regions.

Given the strong inference from our results that N. obtusa is altering the biogeochemical fate of oxygen and phosphorus in Lake Scugog, we propose that $N$. obtusa is acting like an ecosystem engineer of internal biogeochemical processes. An ecosystem engineer is defined as a non-human organism that has direct or indirect effects on ecosystem processes, resulting in significant alterations to ecosystem structure and function. With increasing biomass and dominance in aquatic weed beds, $N$. obtusa may be reducing water-column mixing and exchange with atmospheric oxygen. Although depleted near-bed DO is known to drive internal phosphorus loading in lakes, there is also the negative impact that water column hypoxia-anoxia can have on biota. Studies are now emerging that show the negative effects of N. obtusa on aquatic communities (e.g., Brainard and Schulz, 2017; Harrow-Lyle T. J. and Kirkwood A. E., 2020; Ginn et al., 2021), but much remains unknown about the effects of N. obtusa on the aquatic food web, especially fish. Considering the extent of hypoxia to anoxia reported here in a lake designated as polymictic (i.e., periodic complete mixing of the water column), this poses serious concerns regarding the quality of sportfish habitat.

These findings not only raise questions about habitat condition in Lake Scugog, but other lakes in the region where $N$. obtusa has become established. With the distribution of $N$. obtusa expanding across Ontario lakes (Harrow-Lyle and Kirkwood, 2021), our study provides clear observational data that raise concerns for biogeochemical cycles, benthic habitat structure, and other biota in invaded lakes. These results also support our previous work, which implicated N. obtusa as a biotic driver of Microcystis blooms in Lake Scugog (Harrow-Lyle T. and Kirkwood A. E., 2020). Here we provide for the first time evidence of a possible mechanism for promoting bloom development, whereby $N$. obtusa drives down benthic DO to facilitate internal-phosphorus loading from sediments as well as possibly propagule germination. Further studies should be conducted to verify if these inferred effects by $N$. obtusa in

\section{REFERENCES}

Atapaththu, K. S. S., Parveen, M., Asaeda, T., and Rashid, M. H. (2018). Growth and Oxidative Stress Response of Aquatic Macrophyte Myriophyllum Spicatum to Sediment Anoxia. Fundam. Appl. Limnol. 191, 289-298. doi:10.1127/fal/ 2018/1070

Bonis, A., and Grillas, P. (2002). Deposition, Germination and Spatio-Temporal Patterns of Charophyte Propagule Banks: A Review. Aquat. Bot. 72 (3-4), 235-248. doi:10.1016/S0304-3770(01)00203-0

Bormans, M., Maršálek, B., and Jančula, D. (2016). Controlling Internal Phosphorus Loading in Lakes by Physical Methods to Reduce Cyanobacterial Blooms: a Review. Aquat. Ecol. 50, 407-422. doi:10.1007/s10452-015-9564-x

Brainard, A. S., and Schulz, K. L. (2017). Impacts of the Cryptic Macroalgal Invader, Nitellopsis Obtusa, on Macrophyte Communities. Freshw. Sci. 36, 55-62. doi:10.1086/689676

Cardinale, B. J., Burton, T. M., and Brady, V. J. (1997). The Community Dynamics of Epiphytic Midge Larvae Across the Pelagic-Littoral Interface: Do Animals
Lake Scugog are occurring in other invaded lake ecosystems in North America, as well as identify possible phosphorus reserves most affected upon biogeochemical cycle alteration. If such notable impacts to lake biogeochemistry are documented region-wide, there will be more certainty that $N$. obtusa is acting as an ecosystem engineer in invaded lakes.

\section{DATA AVAILABILITY STATEMENT}

The raw data supporting the conclusions of this article will be made available by the authors, without undue reservation.

\section{AUTHOR CONTRIBUTIONS}

The authors confirm contribution to the paper as follows: study conceptualization: $\mathrm{TH}-\mathrm{L}, \mathrm{AK}$; funding acquisition: AK; project supervision and administration: AK; investigation: TH-L, data curation: TH-L, formal analysis: $\mathrm{TH}-\mathrm{L}$, and writing-original draft: TH-L, AK. All authors reviewed the results and approved the final version of the manuscript submitted.

\section{FUNDING}

Funding for this research came from an Ontario Trillium Foundation Grow Grant awarded to the Scugog Lake Stewards and a Natural Sciences and Engineering Research Council of Canada (NSERC) Discovery Grant to AK (RGPIN 246150).

\section{ACKNOWLEDGMENTS}

We would like to acknowledge and thank the Mississaugas of Scugog Island First Nation for whose traditional lands and waters are where our study was located. Finally, we thank members of the Scugog Lake Stewards and Kirkwood lab: Eric Anderson, Claire Gibbs, and Erin Smith, for their assistance in the field and laboratory.

Respond to Changes in the Abiotic Environment? Can. J. Fish. Aquat. Sci. 54, 2314-2322. doi:10.1139/f97-138

Chung, S. W., Imberger, J., Hipsey, M. R., and Lee, H. S. (2014). The Influence of Physical and Physiological Processes on the Spatial Heterogeneity of a Microcystis Bloom in a Stratified Reservoir. Ecol. Model. 289, 133-149. doi:10.1016/j.ecolmodel.2014.07.010

Frodge, J. D., Thomas, G. L., and Pauley, G. B. (1990). Effects of Canopy Formation by Floating and Submergent Aquatic Macrophytes on the Water Quality of Two Shallow Pacific Northwest Lakes. Aquat. Bot. 38, 231-248. doi:10.1016/03043770(90)90008-9

Ginn, B. K., Dias, E. F. S., and Fleischaker, T. (2021). Trends in Submersed Aquatic Plant Communities in a Large, Inland lake: Impacts of an Invasion by Starry Stonewort (Nitellopsis Obtusa). Lake Reserv. Manag. 37, 199-213. doi:10.1080/ 10402381.2020.1859025

Ginn, B. K. (2011). Distribution and Limnological Drivers of Submerged Aquatic Plant Communities in Lake Simcoe (Ontario, Canada): Utility of Macrophytes as Bioindicators of lake Trophic Status. J. Great Lakes Res. 37, 83-89. doi:10.1016/j.jglr.2011.03.015 
Green, A. J. (2016). The Importance of Waterbirds as an Overlooked Pathway of Invasion for Alien Species. Divers. Distrib. 22, 239-247. doi:10.1111/ddi.12392

Hackett, R., Caron, J., and Monfils, A. (2014). Status and Strategy for Starry Stonewort (Nitellopsis Obtusa (NA Desvaux) J. Groves) Management. Lansing, Michigan: Michigan Dep. Environ. Qual.

Harrow-Lyle, T. J., and Kirkwood, A. E. (2020a). An Assessment of Lake Scugog Offshore Water Quality and Ecological Condition.

Harrow-Lyle, T. J., and Kirkwood, A. E. (2021). An Ecological Niche Model Based on a Broad Calcium-Gradient Reveals Additional Habitat Preferences of the Invasive Charophyte Nitellopsis Obtusa. Aquat. Bot. 172, 103397. doi:10.1016/ j.aquabot.2021.103397

Harrow-Lyle, T., and Kirkwood, A. E. (2020b). The Invasive Macrophyte Nitellopsis Obtusa May Facilitate the Invasive Mussel Dreissena polymorpha and Microcystis Blooms in a Large, Shallow lake. Can. J. Fish. Aquat. Sci. 77, 1201-1208. doi:10.1139/cjfas-2019-0337

Karol, K. G., and Sleith, R. S. (2017). Discovery of the Oldest Record of Nitellopsis Obtusa (Charophyceae, Charophyta) in North America. J. Phycol. 53, 1106-1108. doi:10.1111/jpy.12557

Kassambara, A. (2020). Ggpubr: "Ggplot2" Based Publication Ready Plots. R package version 0.2. Available at: https://CRAN.R-project.org/package=ggpubr.

Kawartha Conservation (2010). Lake Scugog Environmental Management Plan. Ontario: Lindsay.

Kufel, L., and Kufel, I. (2002). Chara Beds Acting as Nutrient Sinks in Shallow Lakes A Review. Aquat. Bot. 72, 249-260. doi:10.1016/S0304-3770(01)00204-2

Lake, B. A., Coolidge, K. M., Norton, S. A., and Amirbahman, A. (2007). Factors Contributing to the Internal Loading of Phosphorus from Anoxic Sediments in Six Maine, USA, Lakes. Sci. Total Environ. 373, 534-541. doi:10.1016/ j.scitotenv.2006.12.021

Larkin, D. J., Monfils, A. K., Boissezon, A., Sleith, R. S., Skawinski, P. M., Welling, C. H., et al. (2018). Biology, Ecology, and Management of Starry Stonewort (Nitellopsis Obtusa; Characeae): A Red-Listed Eurasian green Alga Invasive in North America. Aquat. Bot. 148, 15-24. doi:10.1016/ j.aquabot.2018.04.003

Midwood, J. D., Darwin, A., Ho, Z.-Y., Rokitnicki-Wojcik, D., and Grabas, G. (2016). Environmental Factors Associated with the Distribution of Non-Native Starry Stonewort (Nitellopsis Obtusa) in a Lake Ontario Coastal Wetland. J. Great Lakes Res. 42, 348-355. doi:10.1016/ j.jglr.2016.01.005

Migula, W. (1897). "Die Characeen Deutschlands, Oesterreichs und der Schweiz; Unter Berücksichtigung aller Arten Europas BT - Kryptogamenflora Von Deutschland, Oesterreich Und Der Schweiz," in Kryptogamenflora Von Deutschland, Oesterreich Und Der Schweiz, 2.

Murphy, J., and Riley, J. P. (1962). A Modified Single Solution Method for the Determination of Phosphate in Natural Waters. Anal. Chim. Acta 27, 31-36. doi:10.1016/S0003-2670(00)88444-5
Neuwirth, E. (2014). RColorBrewer. R Packag. version1.1-2

Ontario Ministry of Environment (1983). Handbook of analytical methods for environmental samples. Laboratory Services and Applied Research Branch, Ontario Ministry of Environment, Toronto, Ontario, Canada.

Pullman, G. D., and Crawford, G. (2010). A Decade of Starry Stonewort in Michigan. NALMS.

QGIS Development Team (2016). QGIS Geographic Information System. Open Source Geospatial Found. Proj.

R Core Team (2019). R: A Language and Environment for Statistical Computing. $R$. Found. Stat. Comput.

Reynolds, C., Miranda, N. A. F., and Cumming, G. S. (2015). The Role of Waterbirds in the Dispersal of Aquatic Alien and Invasive Species. Divers. Distrib. 21, 744-754. doi:10.1111/ddi.12334

Sand-Jensen, K., and Borum, J. (1991). Interactions Among Phytoplankton, Periphyton, and Macrophytes in Temperate Freshwaters and Estuaries. Aquat. Bot. 41, 137-175. doi:10.1016/0304-3770(91)90042-4

Sleith, R. S., Havens, A. J., Stewart, R. A., and Karol, K. G. (2015). Distribution of Nitellopsis Obtusa (Characeae) in New York, U.S.A. Brittonia 67, 166-172. doi:10.1007/s12228-015-9372-6

Unmuth, J. M. L., Lillie, R. A., Dreikosen, D. S., and Marshall, D. W. (2000). Influence of Dense Growth of Eurasian Watermilfoil on Lake Water Temperature and Dissolved Oxygen. J. Freshw. Ecol. 15, 497-503. doi:10.1080/02705060.2000.9663772

Wickham, H. (2016). ggplot2: Elegant Graphics for Data Analysis. doi:10.1007/9783-319-24277-4

Wood, R. D. (1967). Charophytes of North America. A Guide to the Species of Charophyta of North America, Central America and the West Indies. Kingston: Bookstore, Memorial Union University of Rhode Island.

Conflict of Interest: The authors declare that the research was conducted in the absence of any commercial or financial relationships that could be construed as a potential conflict of interest.

Publisher's Note: All claims expressed in this article are solely those of the authors and do not necessarily represent those of their affiliated organizations, or those of the publisher, the editors and the reviewers. Any product that may be evaluated in this article, or claim that may be made by its manufacturer, is not guaranteed or endorsed by the publisher.

Copyright (c) 2021 Harrow-Lyle and Kirkwood. This is an open-access article distributed under the terms of the Creative Commons Attribution License (CC $B Y)$. The use, distribution or reproduction in other forums is permitted, provided the original author(s) and the copyright owner(s) are credited and that the original publication in this journal is cited, in accordance with accepted academic practice. No use, distribution or reproduction is permitted which does not comply with these terms. 